\title{
Anxiety and Attachment Styles: A Systematic Review
}

\author{
Lingjie Guo ${ }^{1}$, Jude Ash ${ }^{2, *}$ \\ ${ }^{1}$ Shenzhen University, Shenzhen, Guangdong 510000, China \\ ${ }^{2}$ Cognition, Emotion, and Emotion Disorders Lab, University of Notre Dame, Notre Dame IN46556, USA \\ "Corresponding author. Email: jude2ash@nd.edu
}

\begin{abstract}
Attachment theory argues that the interaction between individuals and their special others (especially infants to their mothers) in childhood affects how the individuals behave in the face of pressure, threat, and separation, which in turn is related to the individual's mental health. Intimate relationship functioning is associated with various mental health outcomes. Anxiety is an emotion state which is separable yet related to fear. Anxiety is a future-oriented emotion, and fear is an alarm response to present and imminent event. In several studies, specific attachment styles were associated with anxiety disorders. As such, attachment styles may relate to anxiety disorder. The present review aims to analyze the literature on the relationship between adult attachment styles and anxiety in the last three years (2016-2019). It turns out that Secure attachment is negatively associated with anxiety symptoms. By contrast, insecure attachment is positively associated with anxiety symptoms, anxiety disorders, and subtypes of anxiety disorders (correlation coefficient ranged from 0.273 to 0.56 , effect size ranged from -0.11 to 0.37 ). The correlation coefficient of anxious attachment and anxiety ranged from 0.273 to 0.56 , of avoidant attachment and anxiety ranged from zero, no correlation, to 0.3 , despite different group characteristics of individuals (e.g., different mental diseases, with or without
\end{abstract} having perceived parenting).

Keywords: Systematic review, attachment style, anxiety

\section{INTRODUCTION}

\subsection{Attachment styles}

Attachment theory (Bowlby, 1969, 1973, 1980) argues that the interaction between individuals and their special others (especially infants to their mothers) in childhood affects how the individuals behave in the face of pressure, threat, and separation, which in turn is related to the individual's mental health(Ainsworth \& Baker, 1982; Bowlby, 1969, 1973, 1980). According to attachment theory, the interaction between individuals and their special others shapes their Internal working models (IWMs). IWMs refer to schemas of how individuals view themselves and others, that is to say, the habitual interaction patterns of the attached individuals to anticipate, interpret, and guide the reciprocal attachment interactions (Bretherton \& Munholland, 2016). Bowlby $(1969,1973,1980)$ postulated two types of IWMs: the model of self and the model of others, which can both be dichotomized into positive or negative.

Attachment has been conceptualized according to two main models. In the first, attachment was categorized into three main styles: secure, anxious/ambivalent, and avoidant (Ainsworth, Blehar, Waters, and Wall, 1978).According to this model, infants with anxious attachment tend to develop "protest" behaviours, and those with avoidant attachment tend to develop "detachment" behaviours (Ainsworth et al., 1978). Regarding the views

of self and others, individuals with secure attachment describe themselves as approachable, welcomed, and view others are well-intentioned and good-hearted. Those who has anxious/ambivalent attachment feel self-doubting, misunderstood, and underappreciated, and believe others are less willing to commit to a relationship than they actually are. And individuals with avoidant attachment fall somewhere on that spectrum between secure and anxious/ambivalent styles, but mostly closer to anxious/ambivalent (Hazan \& Shaver, 1987).

Bartholomew and Horowitz (1991) described another model of attachment that recognizes four main styles: secure, dismissing, preoccupied, and fearful. Secure individuals are "comfortable with intimacy and autonomy" and have positive views about self and others. Preoccupied individuals are "preoccupied with relationships", and have a negative perspective of self but a positive view of others. Dismissing individuals are "dismissing of intimacy and counter-dependent", having a positive view about self but a negative view of others. Fearful individuals are "fearful of intimacy and socially avoidant" and have negative views about self and others (p. 227).

In addition to the type models mentioned above, two primary dimensions are widely used in the attachment research: anxiety and avoidance (Griffin \& Bartholomew, 1994; Mikulincer, Shaver, \& Pereg, 2003). In the threecategory model, lower scores on each dimension indicate higher secure attachment (Sibley, Fischer, \& Liu, 2005). In the four-category model, secure attachment involves low anxiety and low avoidance, dismissing attachment involves low anxiety and high avoidance, preoccupied attachment involves high anxiety and low avoidance, and 
fearful attachment involves high anxiety and high avoidance (Fraley \& Shaver, 2000).

Attachment styles are related to psychotherapy and psychopathology. For example, a meta-analysis reported lower levels of depression in securely-attached individuals compared to those insecurely-attached(Dagan, Facompré, \& Bernard, 2018).In addition, greater attachment security predicts better post-treatment outcome(Levy, Kivity, Johnson, \&Gooch, 2018).Secure attachment was also associated with prosociality (Gross, Stern, Brett, \& Cassidy, 2017).

\subsection{Anxiety}

Anxiety is an emotion state which is separable yet related to fear (Öhman, 2008). Anxiety is a future-oriented emotion, and fear is an alarm response to present and imminent event (Barlow, 2004). When anxiety symptoms are intensive, recurrent, and affect psychosocial functioning, it is considered as a disorder (Öhman, 2008). In clinical settings, anxiety disorders occur jointly with depression with high comorbidity rates, and nowadays, anxiety is one of the most prevalent mental health disorders around the world (Roy-Byrne et al., 2008). According to the World Health Organization (2017), there are 264 million people in the world currently suffering anxiety disorders. The DSM-V (American Psychiatric Association, 2013) recognizes several anxiety disorders such as: Separation anxiety disorder, selective mutism, social anxiety disorder, panic disorder, agoraphobia, generalized anxiety disorder, and specific phobias. Obsessive Compulsive Disorder (OCD) and PostTraumatic Disorder (PTSD) are excluded from this newest version of DSM.

The term "anxiety" also refers to the anxiety-proneness as a personality trait, which means that individuals with higher levels of anxiety trait have a greater tendency to worry (Spielberger, 2010). As mentioned before, anxiety is also an emotional state. The State-Trait Anxiety Inventory (STAI; Spielberger, 2010) is used to measure both state and trait of anxiety. Hospital Anxiety and Depression Scale (HADS) is another commonly used measure for anxiety or depressive states.

\subsection{Attachment styles and anxiety}

Attachment theory argues that intimate relationships between individuals and their special others will shape how the individual interacts with others and the world (Bowlby, 1969, 1973, 1980). Intimate relationship functioning is associated with various mental health outcomes. For example, relationship distress and discord predict the onset of anxiety disorder (Foran, Whisman, \& Beach, 2015; Whisman \& Baucom, 2011). Moreover, anxiety disorders develop through the pathways of anxious attachment and avoidant attachment (Mikulincer \& Shaver, 2007; Picardi et al., 2013). In several studies, specific attachment styles were associated with anxiety disorders (Dilmac, Hamarta, \& Arslan, 2009; Erozkan, 2009; Erzen \& Odac1, 2016; Manicavasagar, Silove, Marnane, \& Wagner, 2009). As such, attachment styles may relate to anxiety disorder. However, given that there are only a few longitudinal studies, causation has not been supported by evidence.

Despite the importance of the relationship between anxiety and attachment styles, to my knowledge, only one literature review has focused on attachment styles and anxiety. For example, in the reviews which took moderation effect into account, attachment style was one of the moderators in the relationship between childhood adversity and a series of affective disorders, including anxiety disorders (Hoppen \& Chalder, 2018). Attachment styles are also reviewed in social anxiety (Elizabeth et al., 2006; Ledley \& Heimberg, 2006) and anxiety disorders (Esbjørn, Bender, Reinholdt-Dunne, Munck, \& Ollendick, 2012). The relationship between attachment styles and psychosis was also reviewed (Gumley, Taylor, Schwannauer, \& MacBeth, 2014; Korver-Nieberg, Berry, Meijer, \& de Haan, 2014). Only Manning, Dickson, Palmier-Claus, Cunliffe, and Taylor (2017) directly did a systematic review of social anxiety and attachment styles. In addition, most of the previous reviews did not mainly focus on attachment styles and anxiety. Also, the reviews are based upon studies from over three years ago (20162019). To address these gaps in the literature, the present review aims to analyze the literature on the relationship between adult attachment styles and anxiety in the last three years (2016-2019). Since anxiety disorders include several subtypes, measures of different types of anxiety disorder are not the same, a meta-analysis is not applicable. The results of the review are presented narratively.

\section{METHOD}

\subsection{Study eligibility}

Studies meet the following eligibility criteria in the present review: i) the titles and abstracts were viewed to determine whether they fell within the scope of the relationship between attachment styles and anxiety disorders (or any subtype of anxiety disorders); ii) being publicized in last 3 years; iii) conducted in English; iv) adult sample (i.e., 18 years old or older); v) use quantitative rather than qualitative methods. A longitudinal study with sample age varying from adolescence to adulthood is included. Crosssectional and longitudinal designs are both included in the review.

\subsection{Search strategy}

PsycINFO database was searched using the following keywords: Attachment style (anywhere) AND anxiety 
(title). Titles and abstracts of all the eligible articles were of searching are shown in Figure 1. screened to exclude the articles out of the scope. The steps

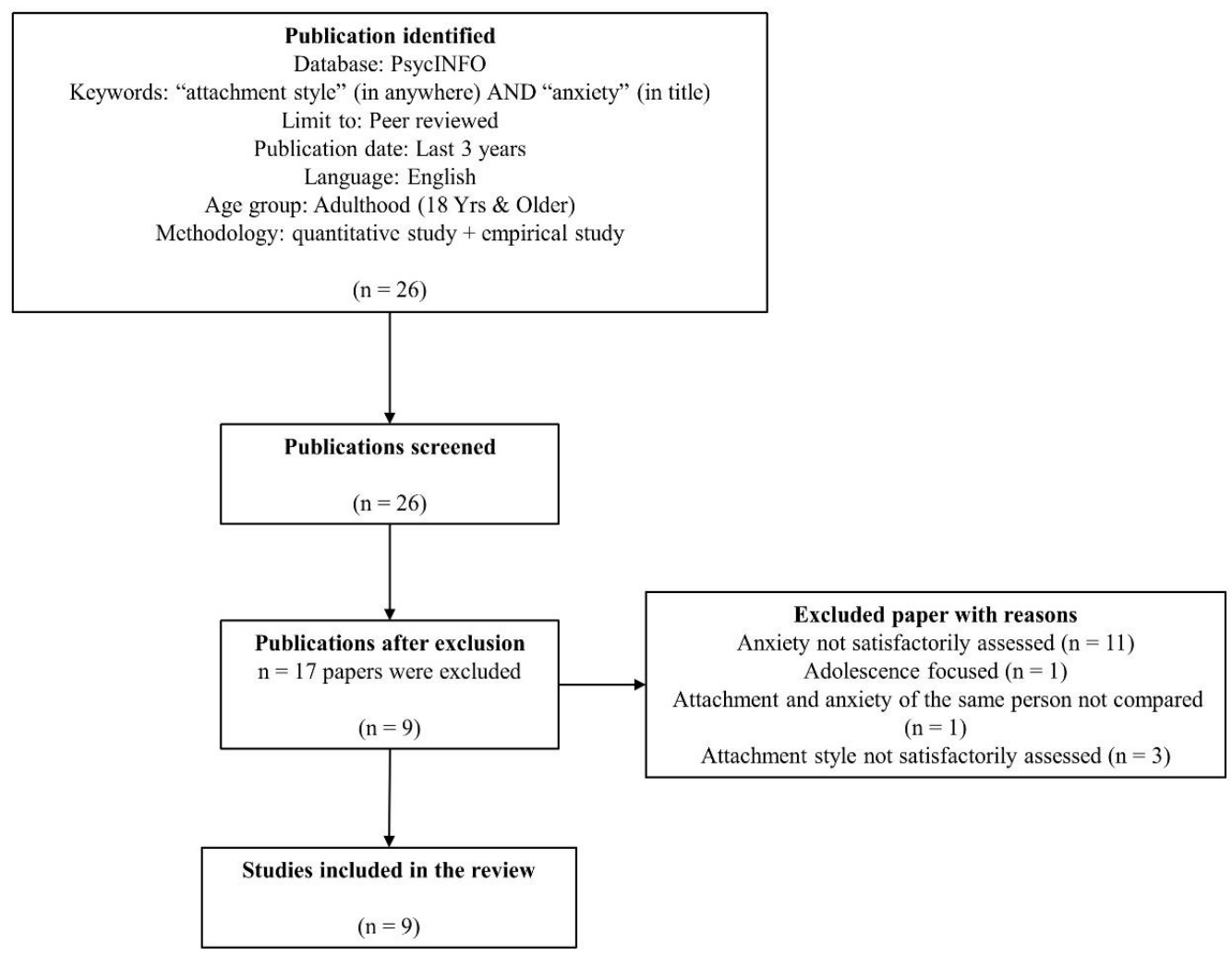

Figure 1 Steps of searching

\section{RESULT}

\subsection{Risk of bias}

The Cochrane Collaboration's tool (Higgins \& Green, 2011) was used to assess the risk bias of the included studies. Six domains of biasness are assessed in the Cochrane Collaboration's tool: selection bias, performance bias, detection bias, attrition bias, reporting bias, and other bias. The assessment tool used here is adapted from Higgins et al. (2011) and Manning et al. (2017).

Unbiased selection of cohort refers to the sample's representativeness of the population (Manning et al., 2017). In the included studies, sample sizes ranged from $\mathrm{n}=52$ to $\mathrm{n}=676$. Due to the limited sampling of some studies, there may be a possibility of selection bias. Also, although all the studies except one did not report the ethnicity of the participants, they are all conducted in seven different countries, which may cause cultural differences.

In $\mathrm{k}=3$ controlled experiments, only one reported using blinded review, but the type of blinding used (single-, double-, or triple-blind) was unclear. Others did not report a blinding design. One study had more women in the experimental group compared to the controlled group, which may cause selection bias.

All the studies used validated measures of attachment styles and anxiety with good reliability, except one that reported a relatively low internal consistency for secure attachment $(\alpha=0.59$; Valikhani, Sarafraz, \&Moghimi, 2018). For anxiety, all the studies but one (Katz \& Hilsenroth, 2017) used self-report questionnaires. Moreover, Katz and Hilsenroth (2017) mentioned that their assessment of anxiety failed to test interrater reliability, and Valikhani, Sarafraz, and Moghimi (2018) indicated that anxiety was assessed when participants were under chemotherapy.

A common potential bias is that only the Experiences in Close Relationships questionnaire (ECR; Brennan, Clark, \& Shaver, 1998), its revised version (ECR-R; Fraley, Waller, \& Brennan, 2000), and the other three-category self-report attachment styles measures were used. Bartholomew (1990) suggested a four-category model, for the model of self and the model of the world both have two valences respectively (positive vs. negative), if the two models are crossed with two valences, then the fourcategory attachment pattern is more precise than the threecategory pattern. The three-category and four-category 
models were also questioned by some researchers (Collins \& Read, 1990; Simpson, 1990). Indeed, some researchers have pointed out the lack of consideration of insecurity subtypes through attachment studies (Fearon \& Roisman, 2017).

None of the studies used power analysis, which may cause bias without sample calculation. It is also worth mentioning that the cross-sectional design was commonly used, so causality cannot be inferred.

\subsection{Study Characteristics}

In total, eight studies were reviewed. Sample sizes ranged from $n=52$ to $n=676$. Except for the control group of one study, the majority $(\mathrm{k}=7)$ of studies had more female than male participants (more than 50\%). Except for one longitudinal study which started from adolescence, participants were older than 18 years. Participants were patients with anxiety disorders in $\mathrm{k}=4$ studies, patients with schizophrenia spectrum disorders in $\mathrm{k}=1$ study, patients with cancer in $\mathrm{k}=1$ study, and non-patients in $\mathrm{k}=2$ studies.

Regarding attachment measurement, $\mathrm{k}=6$ studies used ECR or ECR-R. Relationship Questionnaire (RQ; Bartholomew \& Horowitz, 1991), Adults' Attachment Styles Questionnaire (ASQ-40; Feeney, Noller, \& Hanrahan, 1994), and one modified attachment classification were also used. Concerning the theoretical model of attachment, $\mathrm{k}=6$ studies used the popular threecategory model (secure, anxious, avoidant; Brennan, Clark, \& Shaver, 1998), k=1 study used a modified version (Heinze, Cook, Wood, Dumadag, \& Zimmerman, 2018). Only $\mathrm{k}=1$ study used the four-category model (secure, dismissing, preoccupied, fearful; Katz \&Hilsenroth, 2017) The present review is not only focused on anxiety disorders but its symptoms and subtypes. In total, $\mathrm{k}=2$ studies focused on social anxiety, $\mathrm{k}=3$ focused on anxiety symptoms, $\mathrm{k}=2$ focused on all anxiety disorders, and $\mathrm{k}=1$ focused on death anxiety. The measures of anxiety varied considerably among studies. Examples of questionnaires used to measure anxiety disorders and symptoms included the Social Interaction Anxiety Scale (SIAS; Mattick\& Clarke, 1998), Brief Symptom Inventory (BSI; Derogatis\&Melisaratos, 1983), Overall Anxiety Severity and Impairment Scale (OASIS; Norman, Hami Cissell, Means-Christensen, \& Stein, 2006), Shedler Western Assessment Procedure-200 (SWAP-200;Westen\&Shedler, 1999a, 1999b), Beck Anxiety Inventory (BAI; Beck, Epstein, Brown, \& Steer, 1988), Hospital Anxiety and Depression Scale (HADS; Zigmond\& Snaith, 1983), Templer Death Anxiety Scale (DAS; Templer, 1970), and a validated Chinese version of the State-Trait Anxiety Inventory (STAI; Li \& Qian, 1995). Regarding the study design, the majority used a cross-sectional design, and only one study was longitudinal.

\subsection{Results of individual studies}

Attachment styles were independent variables, dependent variables, and moderators among studies. Attachment styles had no moderation effect on the relationship between social anxiety disorder's cognitive behavioural therapy (CBT) treatment outcome and attention bias (Byrow \& Peters, 2017), and has a moderation effect between exposure to violence and anxiety symptoms (Heinze et al., 2018). Attachment styles were associated with anxiety in $\mathrm{k}=6$ studies, and correlation coefficients of insecure attachment and anxiety ranged from $r=0.273$ to $r=0.56$ (Karpov et al., 2016; Katz \& Hilsenroth, 2017; Nielsen et al., 2017; O'Neill \& Murray, 2016; Valikhani et al., 2018; Xue et al., 2018).

In addition, $\mathrm{k}=2$ studies examined moderation effects. Byrow and Peters (2017) reported that attention bias predicted the CBT therapy outcome of social anxiety disorder, but attachment styles did not moderate the relationship between them. Furthermore, in a longitudinal study conducted from 1994 to 2012, exposure to violence in adolescence positively predicted anxious and depressive symptoms in adulthood, and secure attachment led to a faster decrease in the symptoms during the time (Heinze et al., 2018). Specifically, securely attached individuals had a faster decrease in their mental health symptoms trajectory. Attachment styles were associated with anxiety in $\mathrm{k}=6$ studies. Studies indicated that attachment styles correlated with anxiety disorders (O’Neill \& Murray, 2016), social anxiety (Katz \& Hilsenroth, 2017), and death anxiety (Valikhani et al., 2018). Moreover, $\mathrm{k}=2$ studies found an association between attachment styles and anxiety: Compared to healthy individuals, people with anxiety disorders have higher scores on attachment anxiety and avoidance dimensions (Xue et al., 2018); insecurelyattached individuals have higher levels of death anxiety (Valikhani et al., 2018).Secure attachment is negatively associated with anxiety. On the contrary, insecure attachment is positively associated with anxiety.

However, the subtypes of insecure attachment played a different role. For example, anxiety symptoms were strongly associated with anxious attachment $(\mathrm{r}=0.51, \mathrm{p} \leq$ 0.01 ) and weakly correlated with avoidant attachment $(\mathrm{r}=0.30, \mathrm{p} \leq 0.01$; Nielsen et al., 2017).Furthermore, anxiety symptoms of people with bipolar disorder were correlated to anxious attachment $(\mathrm{r}=0.365, \mathrm{p} \leq 0.001)$ and avoidant attachment $(\mathrm{r}=0.232, \mathrm{p} \leq 0.05)$, whereas people with depression were correlated to anxious attachment $(\mathrm{r}=0.273, \mathrm{p} \leq 0.01)$ and avoidant attachment $(\mathrm{r}=0.203, \mathrm{p} \leq$ 0.05 ), and of people with schizophrenia or schizoaffective disorder were correlated to anxious attachment $(\mathrm{r}=0.35, \mathrm{p}$ $\leq 0.01$ ) but not to avoidant attachment (Karpov et al., 2016).O'Neill and Murray (2016) compared people with and without disabled siblings, and found that anxious attachment was correlated with anxiety disorders in both the experimental (with disabled siblings; $\mathrm{r}=0.56, \mathrm{p} \leq$ 0.001 ) and control group (without disabled siblings; $\mathrm{r}=0.51, \mathrm{p} \leq 0.001$ ), but avoidant attachment showed a weak correlation with anxiety disorders only in the control group $(\mathrm{r}=0.24, \mathrm{p} \leq 0.01)$. In a study that reported effect 
sizes, anxious attachment predicted death anxiety but secure and avoidant did not (Valikhani et al., 2018), and the SWAP Social Anxiety/Avoidance Scale (SWAPSAAS) derived from SWAP-200 (Westen \& Shedler, 1999a, 1999b) was reported correlated with secure attachment (in RQ measure; $\mathrm{r}=-0.39, \mathrm{p}=0.004 ; \beta=-0.41$, $\mathrm{p}=0.02$ ), anxious attachment (in ECR-R measure; $\mathrm{r}=0.41$, $\mathrm{p}=0.003 ; \beta=0.37, \mathrm{p}=0.055$ ), fearful attachment (in RQ measure; $\mathrm{r}=0.27, \mathrm{p}=0.06 ; \beta=-0.03, \mathrm{p}=0.84)$, and avoidant attachment (in ECR-R measure; $r=0.24, p=0.09 ; \beta=-0.11$, $\mathrm{p}=0.563$ ), but it had no significant correlation with preoccupied and dismissive subtypes in attachment (Katz \& Hilsenroth, 2017)

\section{CONCLUSION}

The present review aims at exploring the relationship between anxiety and attachment styles, including other relevant factors. The studies included in the review also considered the daily experiences (e.g., exposure to violence, perceived parenting), cognition (e.g., attention bias, cognitive behavioural therapy, differentiation of self), emotion (e.g., self-control, emotion regulation), and other mental disorders (e.g., depression, schizoaffective disorder, bipolar disorder). It may be because of the comorbidity of anxiety disorder with mood disorder and depression (Roy-Byrne et al., 2008; Yerevanian, Koek, \& Ramdev, 2001).

Secure attachment is negatively associated with anxiety symptoms. One study that regarded attachment styles as moderator concluded that securely-attached individuals decrease faster in mental health symptoms. By contrast, insecure attachment is positively associated with anxiety symptoms, anxiety disorders, and subtypes of anxiety disorders (correlation coefficient ranged from 0.273 to 0.56 , effect size ranged from -0.11 to 0.37 ). ECR, which categorizes attachment styles as secure, insecure-anxious, and insecure-avoidant, is used in all the included studies to measure the attachment styles. So, the insecure attachment styles discussed here are anxious and avoidant. Among insecure attachments, anxious attachment was more significant than avoidant attachment when correlated with anxiety. According to the reported data, the correlation coefficient of anxious attachment and anxiety ranged from 0.273 to 0.56 , of avoidant attachment and anxiety ranged from zero, no correlation, to 0.3 , despite different group characteristics of individuals (e.g., different mental diseases, with or without having perceived parenting). Also, because the three-category attachment was most widely adopted, the subtypes from the four-category (secure, fearful, preoccupied, and dismissive) were only discussed in one study. However, the results of insecure attachment in four-category attachment were consistent with other studies: anxious attachment had a stronger correlation with anxiety, fearful attachment is weaker than anxious attachment, and dismissing and preoccupied attachment did not correlate.

\subsection{Limitations}

The present review has several limitations. First, the aim of the present review is exploring the relationship between attachment and anxiety. Due to the measures of anxiety symptoms, anxiety disorders, and subtypes of anxiety disorders are different, meta-analysis cannot be used. Second, the studies included focused on other variables besides anxiety and attachment, which was not targeted enough. Third, the studies being reviewed suffer risk of bias, which may prejudice the final conclusions. Fourth, the four-category attachment was only measured in one study, which made the review lack consideration of insecurity subtypes. Finally, only one longitudinal study is reviewed, so we still do not have enough evidence to indicate the causality.

\subsection{Future directions}

The association between attachment and anxiety has been reported, but the causation still had not been revealed. So, longitudinal studies can be designed to investigate the causation of attachment and anxiety. In insecure attachment subtypes, since anxious attachment had high correlation coefficients with anxiety. So, future studies can try to find out what causes the difference between anxious attachment and other insecure subtypes when associating with anxiety. Also, the four-category attachment measures can be used to determine the relationship between anxiety and the more precise insecure attachment subtypes. Finally, since attachment styles are associated with mental health, it is worthy of finding out the therapeutic effect of attachment theory in mental diseases.

\section{REFERENCES}

[1] Ainsworth, \& Baker, C. D., Effects of illumination changes on infant monkey contacts with surrogates, The Psychological Record, 32(4) (1982) 513-518. DOI: https://doi.org10.1007/BF03394809

[2] Ainsworth, M. D. S., Blehar, M. C., Waters, E., \& Wall, S, Patterns of attachment: A psychological study of the strange situation, 1978 . DOI: https://doi.org/10.4324/9780203758045

[3] American Psychiatric Association, Diagnostic and statistical manual of mental disorders (DSM-5®): American Psychiatric Pub, 2003. DOI: https://doi.org/10.4324/9780429473678

[4] Barlow, D. H., Anxiety and its disorders: The nature and treatment of anxiety and panic: Guilford press, 2004. DOI: https://doi.org/10.1002/smi.941

[5] Bartholomew, K., Avoidance of intimacy: An attachment perspective. Journal of Social and Personal relationships, $7(2) \quad(1990)$ 147-178. DOI: https://doi.org/10.1177/0265407590072001 
[6] Bartholomew, K., \& Horowitz, L. M., Attachment styles among young adults: a test of a four-category model, Journal of personality and social psychology, 61(2) (1991) 226. DOI: https://doi.org/10.1037//0022-3514.61.2.226

[7] Beck, A. T., Epstein, N., Brown, G., \& Steer, R. A., An inventory for measuring clinical anxiety: psychometric properties. Journal of consulting and clinical psychology, 56(6) (1988) 893. DOI: https://doi.org/10.1037//0022006X.56.6.893

[8] Bowlby, J, Attachment and loss: Vol. 1. Attachment: New York: Basic Books, 1969.

[9] Bowlby, J., Attachment and loss: Vol. 2. Separation: Anxiety and anger: New York: Basic Books, 1973.

[10] Bowlby, J., Attachment and loss: Vol. 3. Loss: New York: Basic Books, 1980.

[11] Brennan, K. A., Clark, C. L., \& Shaver, P. R., Selfreport measurement of adult attachment: An integrative overview, 1998.

[12] Bretherton, I., Attachment theory: Retrospect and prospect, Monographs of the society for research in child development, 50(1-2) (1985) 3-35. DOI: https://doi.org/10.2307/3333824

[13] Bretherton, I., \& Munholland, K. A., The internal working model construct in light of contemporary neuroimaging research, Handbook of attachment: Theory, research, and clinical applications, 2016, pp. 63-88.

[14] Byrow, Y., \& Peters, L., The influence of attention biases and adult attachment style on treatment outcome for adults with social anxiety disorder, Journal of affective disorders, 2017, pp. 281-288. DOI: https://doi.org/10.1016/j.jad.2017.04.018

[15] Collins, N. L., \& Read, S. J., Adult attachment, working models, and relationship quality in dating couples, Journal of personality and social psychology, 58(4) (1990) 644. DOI: https://doi.org/10.1037/0022-3514.58.4.644

[16] Dagan, O., Facompré, C. R., \& Bernard, K., Adult attachment representations and depressive symptoms: A meta-analysis, Journal of affective disorders, 2018, 236, pp. 274-290. DOI:

https://doi.org/10.1016/j.jad.2018.04.091

[17] Derogatis, L. R., \& Melisaratos, N., The brief symptom inventory: an introductory report. Psychological medicine, 13(3) (1983) 595-605. DOI: https://doi.org/10.1017/S0033291700048017

[18] Dilmac, B., Hamarta, E., \& Arslan, C., Analysing the Trait Anxiety and Locus of Control of Undergraduates in Terms of Attachment Styles, Educational Sciences: Theory and Practice, 9(1) (2009) 143-159. DOI: https://doi.org/10.1177/1028315308318943
[19] Elizabeth, J., King, N., Ollendick, T. H., Gullone, E., Tonge, B., Watson, S., \& Macdermott, S., Social anxiety disorder in children and youth: A research update on aetiological factors, Counselling Psychology Quarterly, 19(2) (2006) 151-163. DOI: https://doi.org/10.1080/09515070600811790

[20] Erozkan, A., The relationship between attachment styles and social anxiety: An investigation with Turkish university students, Social Behaviour and Personality: an international journal, 37(6) (2009) 835-844. DOI: https://doi.org/10.2224/sbp.2009.37.6.835

[21] Erzen, E., \& Odac1, H., The effect of the attachment styles and self-efficacy of adolescents preparing for university entrance tests in Turkey on predicting test anxiety, Educational Psychology, 36(10) (2016) 17281741.

DOI:

https://doi.org/10.1080/01443410.2014.923555

[22] Esbjørn, B., Bender, P. K., Reinholdt-Dunne, M. L., Munck, L. A., \& Ollendick, T., The development of anxiety disorders: Considering the contributions of attachment and emotion regulation, Clinical child and family psychology review, 15(2) (2012) 129-143. DOI: https://doi.org/10.1007/s10567-011-0105-4

[23] Fearon, R. P., \& Roisman, G. I., Attachment theory: progress and future directions, Current Opinion in Psychology, $15 \quad$ (2017) 131-136. DOI: https://doi.org/10.1016/j.copsyc.2017.03.002

[24] Feeney, J. A., Noller, P., \& Hanrahan, M., Assessing adult attachment, 1994

[25] Foran, H. M., Whisman, M. A., \& Beach, S. R., Intimate partner relationship distress in the DSM-5. Family process, 54(1) (2015) 48-63. DOI: https://doi.org/10.1111/famp.12122

[26] Fraley, R. C., \& Shaver, P. R., Adult romantic attachment: Theoretical developments, emerging controversies, and unanswered questions, Review of general psychology, 4(2) (2000) 132-154. DOI: https://doi.org/10.1037//1089-2680.4.2.132

[27] Fraley, R. C., Waller, N. G., \& Brennan, K. A., An item response theory analysis of self-report measures of adult attachment. Journal of personality and social psychology, 78(2) (2002) 350. DOI: https://doi.org/10.1037/0022-3514.78.2.350

[28] Griffin, D. W., \& Bartholomew, K., Models of the self and other: Fundamental dimensions underlying measures of adult attachment, Journal of personality and social psychology, 67(3) (1994) 430. DOI: https://doi.org/10.1037/0022-3514.67.3.430

[29] Gross, J. T., Stern, J. A., Brett, B. E., \& Cassidy, J., The multifaceted nature of prosocial behaviour in children: Links with attachment theory and research, Social 
Development, 26(4) (2017) 661-678. DOI: https://doi.org/10.1111/sode.12242

[30] Gumley, A., Taylor, H., Schwannauer, M., \& MacBeth, A., A systematic review of attachment and psychosis: measurement, construct validity and outcomes. Acta Psychiatrica Scandinavica, 129(4) (2014) 257-274. DOI: https://doi.org/10.1111/acps.12172

[31] Hazan, C., \& Shaver, P., Romantic love conceptualized as an attachment process, Journal of personality and social psychology, 52(3) (1987) 511. DOI: https://doi.org/10.1037//0022-3514.52.3.511

[32] Heinze, J. E., Cook, S. H., Wood, E. P., Dumadag, A. C., \& Zimmerman, M. A., Friendship attachment style moderates the effect of adolescent exposure to violence on emerging adult depression and anxiety trajectories, Journal of youth and adolescence, 47(1) (2018) 177-193. DOI: https://doi.org/10.1007/s10964-017-0729-x

[33] Higgins, J. P., Altman, D. G., Gøtzsche, P. C., Jüni, P., Moher, D., Oxman, A. D., . . . Sterne, J. A., The Cochrane Collaboration's tool for assessing risk of bias in randomised trials, 2011. DOI: https://doi.org/10.1136/bmj.d5928

[34] Higgins, J. P., \& Green, S., Cochrane handbook for systematic reviews of interventions (Vol. 4): John Wiley \& Sons, 2011.2 DOI: https://doi.org/10.1002/9780470712184.ch1

[35] Hoppen, T. H., \& Chalder, T., Childhood adversity as a transdiagnostic risk factor for affective disorders in adulthood: A systematic review focusing on biopsychosocial moderating and mediating variables, Clinical psychology review, 65 (2018) 81-151. DOI: https://doi.org/10.1016/j.cpr.2018.08.002

[36] Karpov, B., Joffe, G., Aaltonen, K., Suvisaari, J., Baryshnikov, I., Näätänen, P., . . . Suominen, K., Anxiety symptoms in a major mood and schizophrenia spectrum disorders. European Psychiatry, 37 (2016) pp. 1-7. DOI: https://doi.org/10.1016/j.eurpsy.2016.04.007

[37] Katz, M., \& Hilsenroth, M. J., Is therapist evaluation of Social Anxiety/Avoidance traits associated with patientreported attachment style? Psychiatry research, 257 (2017) 526-532.

DOI: https://doi.org/10.1016/j.psychres.2017.08.005

[38] Korver-Nieberg, N., Berry, K., Meijer, C. J., \& de Haan, L., Adult attachment and psychotic phenomenology in clinical and non-clinical samples: A systematic review. Psychology and Psychotherapy: theory, research and practice, $\quad 87(2) \quad$ (2014) 127-154. DOI: https://doi.org/10.1111/papt.12010

[39] Ledley, D. R., \& Heimberg, R. G., Cognitive vulnerability to social anxiety, Journal of Social and Clinical Psychology, 25(7) (2006) 755-778. DOI: https://doi.org/10.1521/jscp.2006.25.7.755
[40] Levy, K. N., Kivity, Y., Johnson, B. N., \& Gooch, C. $\mathrm{V}$., Adult attachment as a predictor and moderator of psychotherapy outcome: A meta-analysis. Journal of clinical psychology, 74(11) (2018) 1996-2013. DOI: https://doi.org/10.1002/jclp.22685

[41] Li, W., \& Qian, M. Revision of the State-Trait anxiety inventory with sample of Chinese college students, Paper presented at the Chinese Science Abstracts Series B, 1995.

[42] Manicavasagar, V., Silove, D., Marnane, C., \& Wagner, R., Adult attachment styles in panic disorder with and without comorbid adult separation anxiety disorder, Australian \& New Zealand Journal of Psychiatry, 43(2) (2009) 167-172. DOI: https://doi.org/10.1080/00048670802607139

[43] Manning, R. P., Dickson, J. M., Palmier-Claus, J., Cunliffe, A., \& Taylor, P. J., A systematic review of adult attachment and social anxiety, Journal of affective disorders, $211 \quad$ (2017) 44-59. DOI: https://doi.org/10.1016/j.jad.2016.12.020

[44] Mattick, R. P., \& Clarke, J. C., Development and validation of measures of social phobia scrutiny fear and social interaction anxiety, Behaviour research and therapy, 36(4) (1998) 455-470. DOI: https://doi.org/10.1016/s00057967(97)10031-6

[45] Mikulincer, M., \& Shaver, P. R., Attachment in adulthood: Structure, dynamics, and change: Guilford Press, 2007.

[46] Mikulincer, M., Shaver, P. R., \& Pereg, D., Attachment theory and affect regulation: The dynamics, development, and cognitive consequences of attachmentrelated strategies. Motivation and emotion, 27(2) (2003) 77-102. DOI: https://doi.org/10.1023/A:1024515519160

[47] Nielsen, S. K. K., Lønfeldt, N., Wolitzky-Taylor, K. B., Hageman, I., Vangkilde, S., \& Daniel, S. I. F., Adult attachment style and anxiety-The mediating role of emotion regulation, Journal of affective disorders, 218 (2017) 253-259. DOI: https://doi.org/10.1016/j.jad.2017.04.047

[48] Norman, S. B., Hami Cissell, S., Means-Christensen, A. J., \& Stein, M. B., Development and validation of an overall anxiety severity and impairment scale (OASIS), Depression and anxiety, 23(4) (2006) 245-249. DOI: https://doi.org/10.1002/da.20182

[49] O’Neill, L. P., \& Murray, L. E., Perceived parenting styles fail to mediate between anxiety and attachment styles in adult siblings of individuals with developmental disabilities, Journal of autism and developmental disorders, 46(9) (2016) 3144-3154. DOI: https://doi.org/10.1007/s10803-016-2859-5 
[50] Öhman, A., Fear and anxiety: overlaps and dissociations. Handbook of emotions, 2018, pp. 709-729. DOI: https://doi.org/

[51] Picardi, A., Caroppo, E., Fabi, E., Proietti, S., Di Gennaro, G., Meldolesi, G. N., \& Martinotti, G., Attachment and parenting in adult patients with anxiety disorders, Clinical practice and epidemiology in mental health: CP \& EMH, 9 (2013) 157. DOI: https://doi.org/10.2174/1745017901309010157

[52] Roy-Byrne, P. P., Davidson, K. W., Kessler, R. C., Asmundson, G. J., Goodwin, R. D., Kubzansky, L., . . . Laden, S. K., Anxiety disorders and comorbid medical illness. Focus, 6(4) (2008) 467-485. DOI: https://doi.org/10.1016/j.genhosppsych.2007.12.006

[53] Sibley, C. G., Fischer, R., \& Liu, J. H., Reliability and validity of the revised experiences in close relationships (ECR-R) self-report measure of adult romantic attachment, Personality and social psychology bulletin, 31(11) (2005) 1524-1536.

DOI: https://doi.org/10.1177/0146167205276865

[54] Simpson, J. A., Influence of attachment styles on romantic relationships, Journal of personality and social psychology, 59(5) (1990) 971. DOI: https://doi.org/10.1037/0022-3514.59.5.971

[55] Spielberger, C. D., State-Trait anxiety inventory. The Corsini encyclopedia of psychology, 2010, 1-1. DOI: https://doi.org/10.1007/978-3-319-28099-8_950-1

[56] Templer, D. I., The construction and validation of a death anxiety scale, The Journal of general psychology, 82(2) (1970)165-177. DOI: https://doi.org/1010.1080/00221309.1970.9920634

[57] Valikhani, A., Sarafraz, M. R., \& Moghimi, P., Examining the role of attachment styles and self-control in suicide ideation and death anxiety for patients receiving chemotherapy in Iran, Psycho-oncology, 27(3) (2018) 1057-1060. DOI: https://doi.org/10.1002/pon.4466

[58] Westen, D., \& Shedler, J., Revising and assessing Axis II, Part I: Developing a clinically and empirically valid assessment method, American Journal of Psychiatry, 156(2) (1999) 258-272. DOI: https://doi.org/10.1176/ajp.156.2.258

[59] Westen, D., \& Shedler, J., Revising and assessing Axis II, Part II: Toward an empirically based and clinically useful classification of personality disorders, American Journal of Psychiatry, 156(2) (1999) 273-285. DOI: https://doi.org/10.1176/ajp.156.2.273

[60] Whisman, M. A., \& Baucom, D. H. Intimate relationships and psychopathology, Clinical child and family psychology review, 15(1) (2012) 4-13. DOI: https://doi.org/10.1007/s10567-011-0107-2
[61] World Health Organization. (2017). Depression and other common mental disorders: global health estimates. Retrieved from

[62] Xue, Y., Xu, Z. Y., Zaroff, C., Chi, P., Du, H., Ungvari, G. S., . . . Xiang, Y. T., Associations of differentiation of self and adult attachment in individuals with anxiety-related disorders, Perspectives in psychiatric care, 54(1) (2018) 54-63. DOI: https://doi.org/10.1111/ppc.12200

[63] Yerevanian, B. I., Koek, R. J., \& Ramdev, S., Anxiety disorders comorbidity in mood disorder subgroups: data from a mood disorders clinic, Journal of affective disorders, 67(1-3) (2001) 167-173. DOI: https://doi.org/10.1016/S0165-0327(01)00448-7

[64] Zigmond, A. S., \& Snaith, R. P., The hospital anxiety and depression scale, Acta Psychiatrica Scandinavica, 67(6) (1983) 361-370. DOI: https://doi.org/10.1111/j.1600-0447.1983.tb09716.x 